\title{
GEOMETRICAL PARAMETERS OF E+S PAIRS
}

\author{
Roberto Rampazzo ${ }^{1}$ and Jack W. Sulentic ${ }^{2}$ \\ 1 Osservatorio Astronomico di Brera, Milano - Italy \\ ${ }^{2}$ University of Alabama, Tuscaloosa - USA
}

\section{INTRODUCTION}

- Clues Concerning Galaxy Formation. Local environmental conditions (i.e. density and angular momentum properties of protogalactic clouds) are thought to be factors affecting the ultimate morphology of a galaxy. The existence of significant numbers of mixed morphology $(\mathrm{E} / \mathrm{S} 0+\mathrm{S})$ pairs of galaxies would represent a direct challenge to this idea unless all early-type components are formed by mergers. We wish to isolate candidate $\mathrm{E}+\mathrm{S}$ pairs for detailed study with several questions in mind:

a) Are most of the pairs true E+S systems OR, as the theory would suggest more morphologically concordant pairs involving primarily late-type or disky galaxies alone (i.e. misclassified lenticulars)?

b) Assuming that many of the pairs are $\mathrm{E}+\mathrm{S}$, do their properties differ in any way from $\mathrm{E}$ and $\mathrm{S}$ galaxies in the field?

c) Is their evidence that $\mathrm{E}$ galaxies in mixed pairs are preferentially merger products?

- Interaction Induced Activity. Evidence has accumulated at optical, IR and radio wavelengths for the inducement of enhanced disk and nuclear activity in galaxies due to environment. Boxy isophotes are supposed to be the result of cylindrical rotation of a stellar component induced by strong interactions such as the merging of dwarf galaxies with a giant disk object or collision of equal size members of a pair under special inpact condition (Binney and Petrou 1985). S+E pairs offer a unique vantage point from which to study these effects because we have a single gas rich galaxy and a relatively "clean" perturber.

a) Do the early type components of the pairs show systematic evidence for geometrical distortion (i.e. isophotal twisting, boxy isophotes)?

b) If such evidence is observed, does it correlate with any possible measure of interaction (i.e. optical morphology, IRAS emission, apparent separation)?

c) Is it possible that some of the $\mathrm{S}$ components in mixed pairs have spiral structure that was induced by the interaction?

\section{OBSERVATIONS and REDUCTION}

We have observed 22 pairs of mixed morphology galaxies (containing at least one early-type component) selected from a catalog of Sulentic (1988: unpublished) based upon the ESO sky survey. A large fraction of the objects are found in the catalogue of Arp \& Madore (1987). Table 1 summarizes the observed sample and relevant morphological and interaction characteristics. 
Our observational material consists of $385 \times 574-22 \mu \mathrm{m}$ square pixel CCD images in two colors (some also in $\mathrm{U}$ ) obtained at the Cassegrain focus of the $2.2 \mathrm{~m} \mathrm{MPI/ESO}$ telescope. The scale is 0.257 arcsec pixel ${ }^{-1}$. The filters match the Johnson UBV bands.

TABLE 1

MIXED PAIR MORPHOLOGY

\begin{tabular}{|c|c|c|c|c|c|}
\hline $\begin{array}{l}\text { PAIR } \\
\#\end{array}$ & $\begin{array}{c}\text { SEP } \\
(\operatorname{arcmin})\end{array}$ & $\begin{array}{l}\text { IRAS } \\
60 \mu \mathrm{m}\end{array}$ & $\begin{array}{l}\text { HUBBLE } \\
\text { TYPE }\end{array}$ & $\begin{array}{c}\text { COMMENTS } \\
(*=\text { STRONG } 1 / A)\end{array}$ & $\begin{array}{l}\text { INTERACTION } \\
\text { TYPE }\end{array}$ \\
\hline $\begin{array}{c}5 \\
8 \\
9 \\
11 \\
12 \\
13 \\
18 \\
31 \\
53 \\
54 \\
64 \\
69 \\
70 \\
86 \\
87 \\
90 \\
96 \\
97 \\
104 \\
108 \\
109 \\
115\end{array}$ & $\begin{array}{l}0.9 \\
0.6 \\
0.9 \\
0.6 \\
1.2 \\
0.5 \\
1.3 \\
1.6 \\
2.1 \\
0.5 \\
1.4 \\
0.4 \\
0.4 \\
1.2 \\
0.4 \\
1.0 \\
0.5 \\
0.8 \\
1.0 \\
0.6 \\
0.4 \\
0.3\end{array}$ & $\begin{array}{l}2.68 \\
0.53\end{array}$ & $\begin{array}{c}\text { E+S } \\
\text { SO+S } \\
\text { E+S } \\
\text { E+S } \\
\text { E+SBO } \\
\text { E/SO+SO } \\
\text { E+S } \\
\text { E+S } \\
\text { E+SBO } \\
\text { E+S } \\
\text { E+S } \\
\text { E+S } \\
\text { E+S } \\
\text { E+S } \\
\text { E+S } \\
\text { SBO+S } \\
\text { E/SO+S } \\
\text { E+S } \\
\text { E+S } \\
\text { E/SO+SO } \\
\text { MULTI/MERGER? } \\
\text { E/SO+SO }\end{array}$ & $\begin{array}{c}\text { EARLY PAIR } \\
\text { DISKY PAIR } \\
\text { I/A ARMS } \\
* \\
\text { EARLY PAIR } \\
* \\
* \\
* \\
\text { * } \\
\text { DISKY PAIR } \\
\text { *DISKY PAIR } \\
\text { *I/A ARMS } \\
\text { EARLY PAIR } \\
\text { *E+S? } \\
\text { *DISKY PAIR }\end{array}$ & $\begin{array}{c}\text { LIN(brtta) } \\
\text { DIS(1) } \\
\text { DIS(1) } \\
\text { DIS(1) } \\
\text { JUS } \\
\text { JUS } \\
\text { LIN(br+ta) } \\
\text { DIS(1) } \\
\text { JUS } \\
\text { DIS(1) CONTACT } \\
\text { JUS } \\
\text { DIS(1) } \\
\text { DIS(1) CONTACT } \\
\text { JUS } \\
\text { LIN(br) } \\
\text { JUS } \\
\text { ATM(am) CONTACT } \\
\text { LIN(br+ta) } \\
\text { DIS(1) SHELL } \\
\text { DIS(1) SHELL? } \\
\text { ATM(sh) CONTACT } \\
\text { DIS(1) CONTACT }\end{array}$ \\
\hline
\end{tabular}

During the observing run we had variable seeing conditions $(0.8 \leq \sigma \leq 2.0$ arcsec). All frames were pre-processed (bias removal, flat-fielding, and cleaning. Galaxy isophotes were interpolated with ellipses using the NMP package (cf. Fasano \& Bonoli 1989) in use at the Observatory of Brera. We operated on the original images with an adaptive filter (cf. Caon et al. 1989) in order to reach the faintest possible level in the outskirts of the galaxies. Fig. 1 shows an example of the geometrical profiles obtained in $\mathrm{U}$ (circles), $\mathrm{B}$ (stars) and $\mathrm{V}$ (squares). $\theta$ is the position angle of the major axis, ( $r=a=$ semi-major axis), measured $\mathrm{NE} ; \epsilon=1-b / a$ is the ellipticity of the isophotes; $a(4) / a$ is the fourth cosine coefficient of the Fourier series expansion of the deviation from a pure ellipse divided by the actual semi-major axis. This latter is an isophote shape parameter the sign of which indicates boxy $(a(4)<0)$ or disky $(a(4)>0)$ even if its absolute value depends upon projection effects.

In Table 2 we report the relevant geometrical properties of the galaxies. We list the maximum values measured for the ellipticity and the a(4)/a shape parameter together with the total measured twisting along the profile beyond the seeing disk (we set an inner limit of 3 arcsec). An asterisk indicates objects in which $\mathrm{a}(4) / \mathrm{a}$ is neither predominantly boxy nor disky. 
TABLE 2

GEOMETRICAL PARAMETERS

\begin{tabular}{|c|c|c|c|c|c|c|c|c|c|c|c|}
\hline CODE & $\mathbf{B}_{T}$ & $\left(\begin{array}{c}\mathrm{Cz} \\
\left(\mathrm{km} \mathrm{s}^{-1}\right)\end{array}\right.$ & $\mathbf{U}$ & $\epsilon_{\max }$ & $v$ & $\mathbf{u}$ & $\underset{\text { B }}{\Delta \text { P.A. }}$ & $v$ & $\mathbf{u}$ & $\underset{B}{a(4) / a_{\max }} \times 100$ & $v$ \\
\hline $\begin{array}{l}5 \\
5\end{array}$ & & & & $\begin{array}{l}0.28 \\
0.39\end{array}$ & $\begin{array}{l}0.32 \\
0.35\end{array}$ & & $\begin{array}{l}22.2 \\
16.3\end{array}$ & $\begin{array}{c}8.9 \\
19.7\end{array}$ & & $\begin{array}{r}-1.81 \\
2.99\end{array}$ & $\begin{array}{l}-1.98 \\
2.58\end{array}$ \\
\hline 8 & & & 0.17 & 0.18 & 0.19 & 60.4 & 52.3 & 43.5 & -3.32 & -1.55 & -3.01 \\
\hline 9 & & & 0.10 & 0.13 & 0.14 & 35.4 & 16.8 & 62.1 & 1.15 & -1.19 & -1.85 \\
\hline $\begin{array}{l}11 \\
11\end{array}$ & $\begin{array}{l}16.3 \\
15.1\end{array}$ & & & $\begin{array}{l}0.33 \\
0.72\end{array}$ & $\begin{array}{l}0.34 \\
0.68\end{array}$ & & $\begin{array}{c}9.1 \\
14.6\end{array}$ & $\begin{array}{l}9.9 \\
4.8\end{array}$ & & $\begin{array}{l}-4.18 \\
-3.50\end{array}$ & $\begin{array}{l}-2.91 \\
-2.46\end{array}$ \\
\hline $\begin{array}{l}12 \\
12\end{array}$ & 13.5 & & & $\begin{array}{l}0.11 \\
0.31\end{array}$ & $\begin{array}{l}0.12 \\
0.36\end{array}$ & & $\begin{array}{l}24.7 \\
31.4\end{array}$ & $\begin{array}{l}11.1 \\
31.5\end{array}$ & & $\begin{array}{l}1.46^{*} \\
2.99\end{array}$ & $\begin{array}{c}-0.82 * \\
4.42\end{array}$ \\
\hline $\begin{array}{l}13 \\
13\end{array}$ & $\begin{array}{l}15.2 \\
17.0\end{array}$ & & & $\begin{array}{l}0.16 \\
0.38\end{array}$ & $\begin{array}{l}0.17 \\
0.42\end{array}$ & & $\begin{array}{l}35.0 \\
24.9\end{array}$ & $\begin{array}{l}20.6 \\
18.2\end{array}$ & & $\begin{array}{l}2.45 \\
3.45\end{array}$ & $\begin{array}{l}5.46 \\
1.49\end{array}$ \\
\hline $\begin{array}{l}18 \\
18\end{array}$ & $\begin{array}{l}14.6 \\
14.9\end{array}$ & & & 0.17 & 0.12 & & 45.2 & 19.9 & & $-2.15^{*}$ & $2.11 *$ \\
\hline $\begin{array}{l}31 \\
31\end{array}$ & $\begin{array}{l}15.8 \\
15.1\end{array}$ & & & 0.38 & 0.37 & & 14.2 & 8.0 & & -2.77 & -1.67 \\
\hline $\begin{array}{l}53 \\
53\end{array}$ & $\begin{array}{l}13.2 \\
14.8\end{array}$ & $\begin{array}{l}4925 \\
4700\end{array}$ & $\begin{array}{l}0.37 \\
0.40\end{array}$ & $\begin{array}{l}0.37 \\
0.42\end{array}$ & $\begin{array}{l}0.38 \\
0.45\end{array}$ & $\begin{array}{l}14.2 \\
20.4\end{array}$ & $\begin{array}{l}16.8 \\
70.7\end{array}$ & $\begin{array}{l}17.3 \\
73.6\end{array}$ & $\begin{array}{l}-2.31 \\
-9.19\end{array}$ & $\begin{array}{l}-3.44 \\
-6.00\end{array}$ & $\begin{array}{l}-1.72 \\
-7.25\end{array}$ \\
\hline $\begin{array}{l}54 \\
54\end{array}$ & $\begin{array}{l}13.4 \\
12.6\end{array}$ & $\begin{array}{l}2437 \\
2512\end{array}$ & 0.23 & 0.24 & 0.29 & 10.6 & 33.4 & 29.2 & 2.84 & 2.08 & 1.35 \\
\hline $\begin{array}{l}64 \\
64\end{array}$ & 14.8 & & & $\begin{array}{l}0.12 \\
0.76\end{array}$ & $\begin{array}{l}0.18 \\
0.76\end{array}$ & & $\begin{array}{c}50.0 \\
3.8\end{array}$ & $\begin{array}{c}41.2 \\
5.6\end{array}$ & & $\begin{array}{l}2.18^{*} \\
6.64^{*}\end{array}$ & $\begin{array}{l}1.26^{*} \\
9.14^{*}\end{array}$ \\
\hline $\begin{array}{l}69 \\
69\end{array}$ & $\begin{array}{l}15.0 \\
15.4\end{array}$ & 5970 & $\begin{array}{l}0.23 \\
0.75\end{array}$ & $\begin{array}{l}0.22 \\
0.68\end{array}$ & $\begin{array}{l}0.22 \\
0.71\end{array}$ & $\begin{array}{l}11.8 \\
10.3\end{array}$ & $\begin{array}{l}14.6 \\
8.9\end{array}$ & $\begin{array}{c}11.1 \\
7.3\end{array}$ & $\begin{array}{l}4.26 \\
6.62\end{array}$ & $\begin{array}{l}-2.03 \\
2.82\end{array}$ & $\begin{array}{l}-1.93 \\
0.79\end{array}$ \\
\hline $\begin{array}{l}70 \\
70\end{array}$ & 14.4 & & 0.23 & 0.29 & 0.29 & 19.3 & 7.1 & 14.7 & 1.52 & $-1.86 *$ & $-1.02 *$ \\
\hline $\begin{array}{l}86 \\
86\end{array}$ & & & & 0.26 & 0.26 & & 16.6 & 11.8 & & 2.15 & 2.24 \\
\hline $\begin{array}{l}87 \\
87\end{array}$ & $\begin{array}{l}16.6 \\
16.4\end{array}$ & & 0.27 & 0.31 & 0.38 & 32.3 & 9.6 & 4.2 & 5.47 & $-0.86^{*}$ & $-1.35^{*}$ \\
\hline 90 & & & 0.28 & 0.35 & 0.34 & 69.1 & 64.9 & 77.7 & 5.72 & 4.80 & 4.06 \\
\hline 96 & & & & 0.34 & 0.32 & & 9.9 & 7.5 & & -4.18 & -2.45 \\
\hline 97 & & & 0.18 & 0.30 & 0.30 & 16.4 & 22.7 & 23.4 & 2.23 & 4.60 & 3.22 \\
\hline $\begin{array}{l}104 \\
104\end{array}$ & & & 0.29 & 0.30 & 0.27 & 12.4 & 12.5 & 7.4 & 2.32 & 3.26 & 0.92 \\
\hline $\begin{array}{l}108 \\
108\end{array}$ & & & & $\begin{array}{l}0.11 \\
0.38\end{array}$ & $\begin{array}{l}0.11 \\
0.34\end{array}$ & & $\begin{array}{l}56.6 \\
31.8\end{array}$ & $\begin{array}{l}56.9 \\
35.3\end{array}$ & & $\begin{array}{c}-1.37^{*} \\
3.71^{*}\end{array}$ & $\begin{array}{l}1.14^{*} \\
3.10^{*}\end{array}$ \\
\hline 109 & 14.4 & & & 0.22 & 0.22 & & 9.7 & 14.4 & & -1.42 & -5.95 \\
\hline $\begin{array}{l}115 \\
115\end{array}$ & $\begin{array}{l}15.2 \\
14.7\end{array}$ & & & $\begin{array}{l}0.17 \\
0.55\end{array}$ & $\begin{array}{l}0.21 \\
0.56\end{array}$ & & $\begin{array}{l}52.1 \\
30.3\end{array}$ & $\begin{array}{l}61.3 \\
31.3\end{array}$ & & $\begin{array}{l}-1.28 \\
-3.01\end{array}$ & $\begin{array}{r}-1.69 \\
-2.76\end{array}$ \\
\hline
\end{tabular}




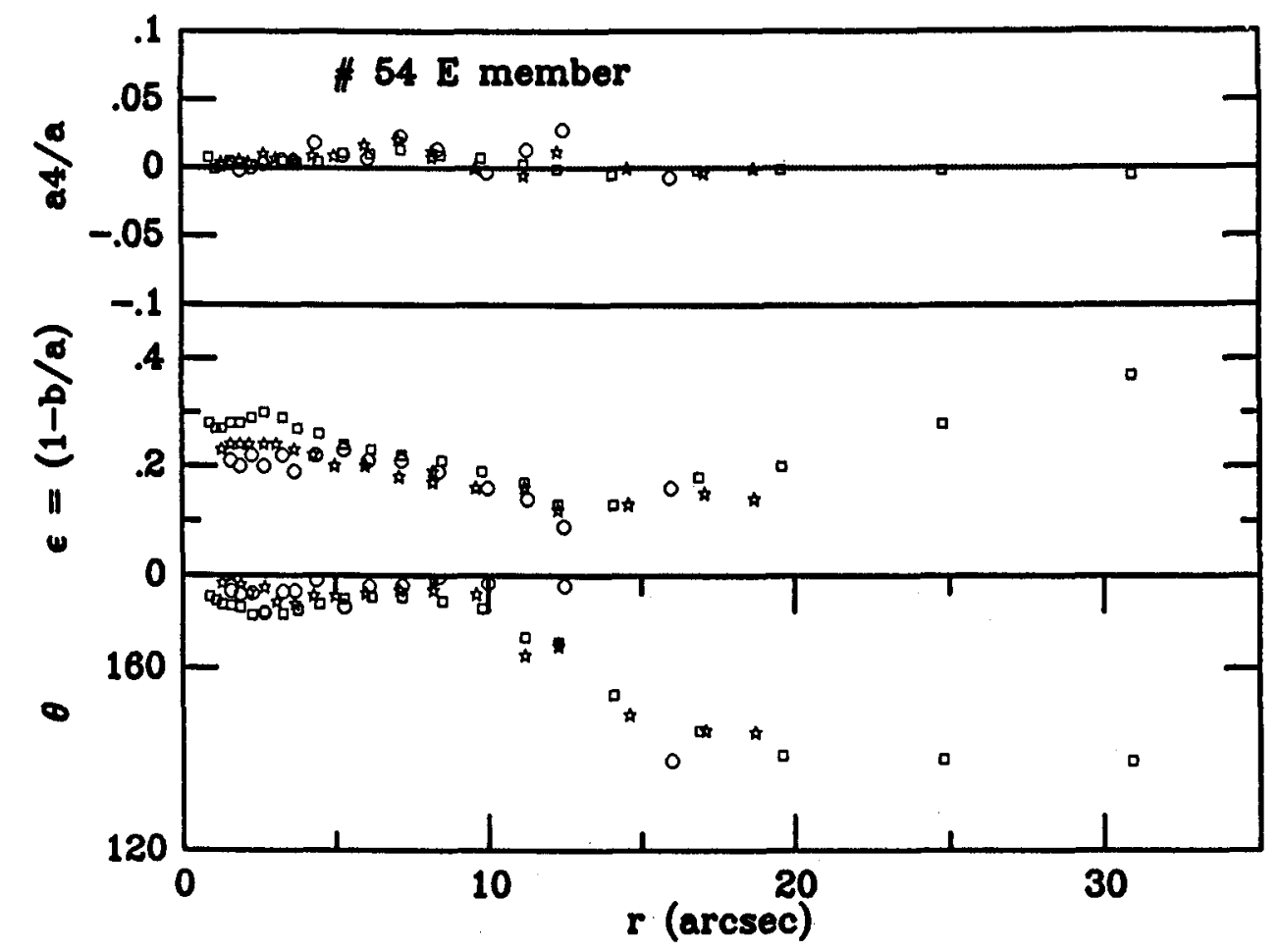

FIG. 1 Pair 54 (E = NGC 6483). Twisting (lower), ellipticity (middle) and shape (upper) profiles as function of the isophotal semi-major axis (for detailed explanations cf. text).

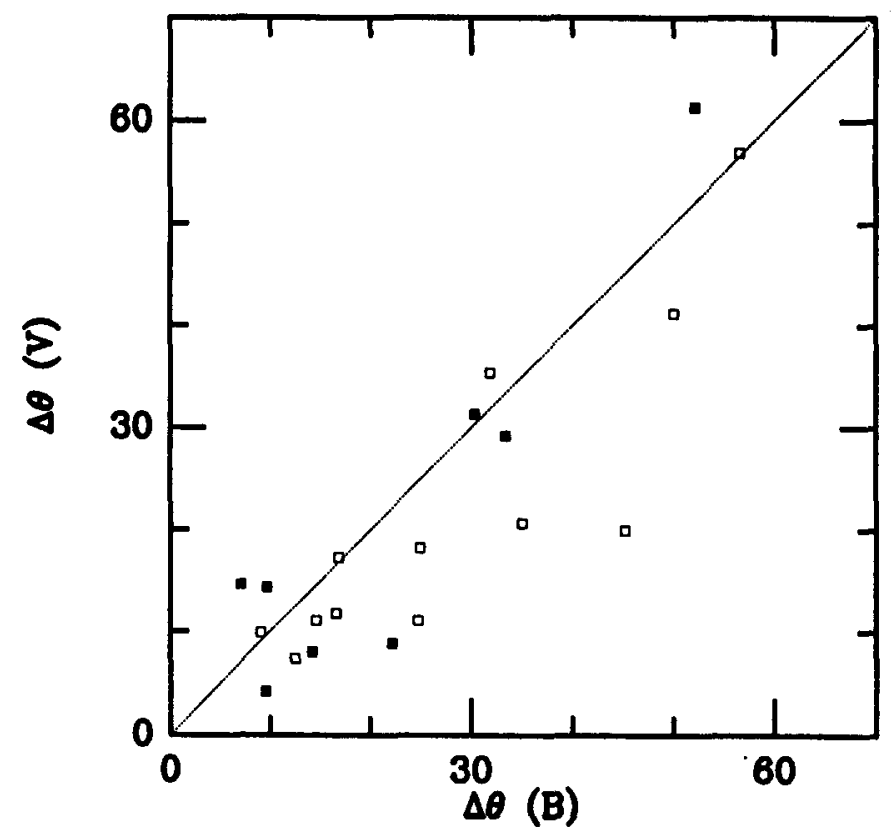

FIG. 2 Comparison between the total measured twisting, $\theta$, in the $B$ and $V$ bands for early-type objects in pairs. Strongly visibly interacting objects are marked as solid squares.

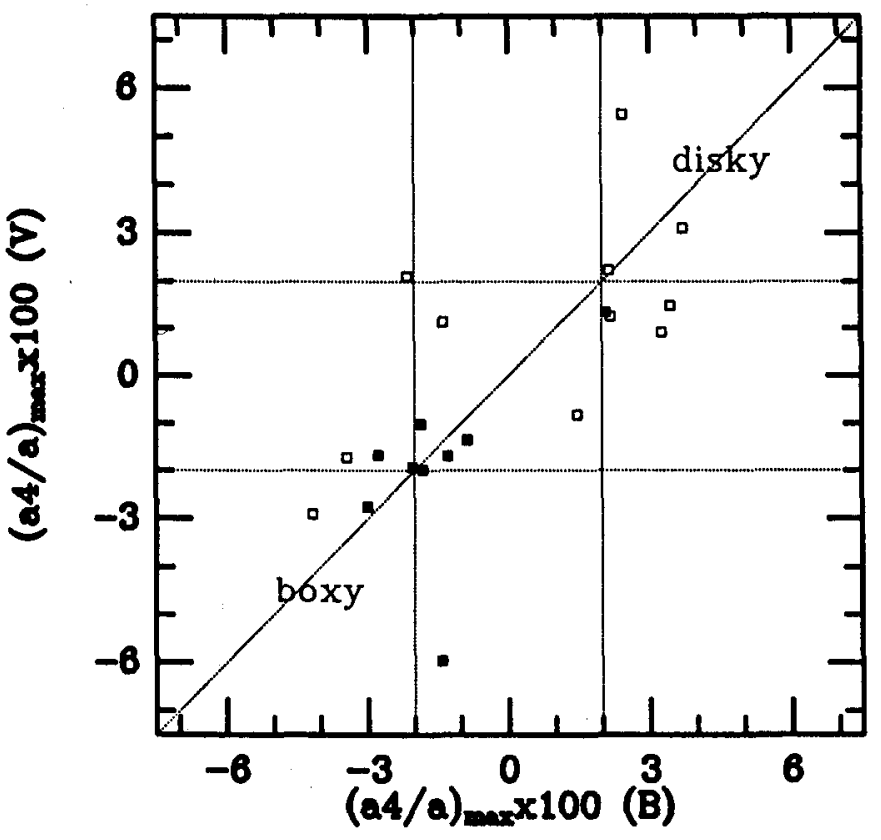

FIG. 3 Comparison between the shape parameter $a 4 / a$ in the $B$ and $V$ bands for early-type objects in pairs. Strongly visibly interacting galaxies are marked as solid squares. 


\section{RESULTS}

\section{- Clues Concerning Galaxy Formation.}

a) We find a large number of true mixed pairs with $13 / 22 \mathrm{E}+\mathrm{S}$ pairs in the present sample. The remaining objects include 5 disk pairs (composed of S0 and S members) and 3 "early-type" pairs comprising $\mathrm{E}$ and $\mathrm{S} 0$ members. We estimate that between 25 and $50 \%$ of the pairs in any complete sample will be of the E+S type. This suggests that 100-200 such pairs exist on the sky brighter than $\mathrm{m}_{p g}=16.0$.

b) We find no global evidence for a difference between $\mathrm{E}$ members of this sample and those in more general samples (e.g. Bender et al. 1989). In particular, we find that about $30 \%$ of the early-type galaxies cannot be classified either predominantly boxy or disky because the a(4)/a profile shows 1) both of these features at a comparable level or 2) does not show any significant trend.

Isophotal twisting (Fig. 2) is observed with a range and distribution consistent with general samples $\left(\triangle \mathrm{PA}\right.$ between $\left.0-70^{\circ}\right)$. Two spirals show significant twisting in their bulge components.

c) We observe two early-type components with shell structure and at least 6 objects with twisting values greater than about $30^{\circ}$. Countering any attempt to ascribe all or most of these features to merger events is the low detection rate in the IRAS catalog especially for a sample of pairs with $\mathrm{V}_{o}$ generally less than $10^{4} \mathrm{~km} \mathrm{~s}^{-1}$.

\section{- Interaction Induced Activity.}

a) About $40 \%$ of early-type components show predominantly boxy isophotes while $30 \%$ show disky ones at or near the $2 \%$ level (measured by the a(4)/a parameter). As mentioned above, both $\mathrm{E}$ and $\mathrm{S}$ components show significant isophotal twisting.

b) The presence of disky isophotes or isophotal twisting does not appear to correlate with strength of interaction. We divided the sample into "strong" and moderate-weak interactors based upon optical morphology. Early-type systems in the strong interaction class show a distinct preference for boxy isophotes (Fig. 3: solid squares) and a weaker avoidance for disky ones. Figure 3 shows this tendency in both $B$ and $V$ bands. Amplitude of isophotal twisting does not appear to correlate with our measure of interaction strength (Figure 2: solid squares).

Three of the $S$ components of our $E+S$ pair sample show spiral structure comprising very open spiral arms not associated with a disk component. If these objects were not originally spirals then some E+S pairs may be "created" by the interaction process.

\section{References}

Arp, H.C. and Madore, B. 1987: A Catalogue of Southern Peculiar Galaxies and Associations, Cambridge Univ. Press.

Bender, R., Surma, P., Döberainer, S. Möllenhoff, C. and Madejsky, R. 1989: Astron. \& Astrophys., 217, 35.

Binney, J.J and Petrou, M. 1985: M.N.R.A.S., 214, 449.

Caon, N., Capaccioli, M. and Rampazzo, R. 1989: Astron. \& Astrophys. Sup. Ser., submitted.

Fasano, G. and Bonoli, C. 1989:Astron. \& Astrophys. Sup. Ser., 79, 291. 